2012-09-28

\title{
An environmental assessment of risk in achieving good environmental status to support regional prioritisation of management in Europe
}

Breen, $\mathrm{P}$

http://hdl.handle.net/10026.1/3406

10.1016/j.marpol.2012.02.003

Marine Policy

Elsevier BV

All content in PEARL is protected by copyright law. Author manuscripts are made available in accordance with publisher policies. Please cite only the published version using the details provided on the item record or document. In the absence of an open licence (e.g. Creative Commons), permissions for further reuse of content should be sought from the publisher or author. 
An environmental assessment of risk in achieving Good Environmental Status to support regional prioritisation of management in Europe.

Breen P. ${ }^{1}$, Robinson L.A. ${ }^{2}$, Rogers S.I. ${ }^{1}$, Knights A.M. ${ }^{2}$, Piet G. ${ }^{3}$, Churilova T. ${ }^{4}$, Margonski P. ${ }^{5}$, Papadopoulou N. ${ }^{6}$, Akoglu E. ${ }^{7}$, Eriksson A. ${ }^{8}$, Finenko Z. ${ }^{4}$, Fleming-Lehtinen V ${ }^{8}$., Galil B. ${ }^{9}$, Goodsir F..$^{*}$, Goren M. ${ }^{10}$, Kryvenko O. ${ }^{4}$, Leppanen J.M. ${ }^{8}$, Markantonatou V. ${ }^{6}$, Moncheva S. ${ }^{11}$, Oguz T ${ }^{7}$, Paltriguera L. ${ }^{1}$, Stefanova K. ${ }^{11}$, Timofte F. ${ }^{12}$, and Thomsen F. ${ }^{1}$

*Corresponding author.Cefas, Pakefield Road,Lowestoft.NR33 0HT.Email:freya.goodsir@cefas.co.uk.Tel:01502524420

1. Centre for Environment, Fisheries and Aquaculture Science (Cefas). Pakefield Road, Lowestoft. NR33 0HT. UK.

2. School of Environmental Sciences, University of Liverpool, Nicholson Building, Liverpool. L69 7GP. UK.

3. Institute for Marine Resources and Ecosystem Studies (IMARES). Ijmuiden, Haringkade 1, 1976 CP Ijmuiden, The Netherlands.

4. A.O. Kovalevskiy Institute of Biology Of Southern Seas. National Academy of Sciences of Ukraine 2, Nakhimov av., Sevastopol, 99011, Crimea, Ukraine.

5. National Marine Fisheries Research Institute, Department of Fisheries Oceanography and Marine Ecology, ul. Kollataja 1,81-332 Gdynia, Poland.

6. Hellenic Centre for Marine Research, Institute of Marine Biological Resources, PO Box 2214, Heraklion 71003, Crete.

7. Institute of Marine Sciences, Middle East Technical University. P.O.Box 28, 33731, Erdemli-Mersin, Turkey.

8. Marine Research Centre, Finnish Environment Institue (SYKE), Po Box 140, FI-00251 Helsinki.

9. National Institute of Oceanography, Israel Oceanographic \& Limnological Research (NIO-IOLR), Tel Shikmona, 31080 Haifa, Israel.

10. Department of Zoology, Tel Aviv University. Tel Aviv 69778, Israel.

11. Institute of Oceanology- BAS, 9000 Varna, P.O. Box 152, Bulgaria.

12. National Institute for Marine Research and Development "Grigore Antipa", 900581 Constanta, RO. 
1 An environmental assessment of risk in achieving Good Environmental Status to support regional

2 prioritisation of management in Europe.

\section{$3 \quad$ Abstract}

4 The Marine Strategy Framework Directive (MSFD) aims to achieve Good Environmental Status

5 (GES) in Europe's Seas. The requirement for regional sea authorities to identify and prioritize issues

6 for management has meant that standardized methods to assess the current level of departure from

7 GES are needed. The methodology presented here provides a means by which existing information

8 describing the status of ecosystem components of a regional sea can be used to determine the effort

9 required to achieve GES. A risk assessment framework was developed to score departure from GES

10 for 10 out of the 11 GES descriptors, based on proposed definitions of 'good' status, and current

11 knowledge of environmental status in each of the four regional seas (North-East Atlantic,

12 Mediterranean Sea, Baltic Sea and Black Sea). This provides an approach for regional evaluation of

13 environmental issues and national prioritization of conservation objectives. Departure from GES

14 definitions is described as 'high', 'moderate' or 'low' and the implications for management options and

15 national policy decisions are discussed. While the criteria used in this study were developed

16 specifically for application toward MSFD objectives, with modification the approach could be applied

17 to evaluate other high-level social, economic or environmental objectives.

18

Key-words: risk assessment; status; Marine Strategy Framework Directive; management; GES 
28 Ecosystem-based management (EBM) considers both ecological and human objectives in the 29 exploitation of resources [1]. It aims to maintain ecosystems in a healthy, productive, resilient 30 condition whilst still providing key marine resources for human consumption [2]. As such there are 31 numerous policies and directives which aim to support EBM. In many cases, initiatives have been 32 focused on single species or sectors at a relatively small-scale [3], although larger-scale initiatives 33 have recently been proposed which require an array of different sectors, habitats and species to be 34 considered. Within Europe, the Marine Strategy Framework Directive (MSFD) (2008/56/EC) [4] is 35 one such policy; its key objective is the achievement of Good Environmental Status (GES) in each of 36 the four European regional seas: The North-East Atlantic, The Mediterranean Sea, The Baltic Sea and 37 The Black Sea (Fig. 1) by 2020.

38 The MSFD has used 11 descriptors of GES to broadly describe the natural environment and the 39 pressures related to it. It has placed obligations on Member States to promote GES. There are four 40 main steps in this process; the outcome of which is to support the identification of current aspects of 41 the marine ecosystem under threat and lead to the implementation of management options to mitigate 42 impacts and support sustainable use of marine ecosystems. The steps include: (1) completing an initial 43 assessment of the current state of marine waters (by 2012); developing targets and indicators to 44 demonstrate GES (by 2012); (3) setting up monitoring programmes to assess progress against GES 45 (by 2014); and (4) implementing a programme of measures to help achieve GES (by 2016). The need 46 for cooperation between member states bordering the regional seas, to take forward implementation of 47 the MSFD, is emphasized strongly in the documentation [4]; see summary in [5].

48 Achieving GES may not be possible for all ecosystem components by 2020 (Article 29[4]) and 49 Member States are not required to take steps to mitigate threats when there is no significant risk to the 50 marine environment (Article 11[4]). 'Failure' to meet the Directive's requirements only occurs when 51 management measures are not implemented to address an identified threat (Article 11[4]). The need to 
52 rationalise resource use may lead to the prioritisation of issues by Member States of management 53 measures most likely to have a beneficial effect.

54 Whilst existing ecosystem status assessments are useful in the context for which they were developed, 55 the specific criteria and methodology used to determine status and trends do not allow for easy inter56 comparison across regional seas. The motivation for existing assessments can be wide-ranging and 57 cover topics as diverse as sustainability of fish stocks, coastal, estuarine and whole marine ecosystem 58 condition assessments to predicting potential impacts of future projects, programmes and policies [6]. 59 In addition the assessments may have been undertaken at very different spatial scales adding 60 complexity. For example, national ecosystem assessments may not account for transboundary 61 pressure (e.g. exploitation of fish stocks straddling territorial boundaries) and hence, may 62 underestimate the level of threat at a regional scale. Large-scale ecosystem assessments such as the 63 OSPAR Quality Status Report 2010 [7] by comparison, go some way toward providing a regional 64 overview of potential problem areas. However, differing regional interests and the wide range of goals 65 and objectives of each assessment means that the information available, even if at a similar spatial 66 scale, may not cover all of the issues highlighted by the MSFD's descriptors of GES. Furthermore 67 where the same issues are covered, the objectives and baselines of the assessments may differ.

68 To fulfil the first step of implementing the MSFD and help prioritise monitoring and management, a 69 regional overview of ecosystem status is required which is set around the 11 GES descriptors. To 70 achieve this, existing national and regional assessments must be collated and their outcomes 71 interpreted to form a coherent assessment that can cover all aspects of GES [5, 8]. Here, we present a 72 methodology that can assess the wide range of existing assessments relevant to the different aspects of 73 good environmental status. A risk assessment framework was used to assess the degree of departure 74 of current ecosystem status from proposed definitions of GES, and indicated the likely level of effort 75 required by Member States to achieve GES for each descriptor. Using a combination of existing 76 assessments and/or expert judgement, the major challenges to the GES objectives are identified for 77 each of Europe's four regional seas. The outcomes allow Members States to identify national and 78 regional management priorities to support achievement of GES by 2020. 


\section{$81 \quad 2.1 \quad$ Definition of objectives}

82 Each MSFD Descriptor of GES was defined in the Directive (Annex I, EC, 2008; listed here in

83 Appendix A), but in many cases the definitions failed to provide sufficient detail to determine if GES

84 is likely to be achieved. For example, Descriptor 2 (D2) is defined as "NIS (NIS) introduced by

85 human activities are at levels that do not adversely alter the ecosystems" but it is not clear what would

86 constitute adverse effects on the ecosystem, nor how these might be linked to the distribution or

87 number of NIS.

88 For each of the descriptors assessed (here 10 of the 11 MSFD Descriptors ${ }^{1}$ ) a more detailed definition 89 was developed against which to assess the extent of departure from the current ecosystem status, and 90 thus the risk of failing to achieve the objective.

91 To define GES for each descriptor a number of key documents were consulted. These were: EC

92 Commission Decision Document [9] which lists the indicators required to assess each Descriptor, and

93 Cardoso et al. [10] which informed the Commission Decision Document [9] and draws together

94 advice given by expert task groups set up to review knowledge and understanding of the GES

95 descriptors. These more detailed definitions incorporated specific characteristics associated with

96 achievement of GES to enable interpretation at a regional sea scale (Appendix B).

97

\section{$98 \quad 2.2$ Definition of risk criteria}

99 Having clarified the characteristics associated with achievement of each descriptor, criteria describing 100 high, moderate and low levels of departure from GES were then defined, corresponding with different 101 levels of risk of failing to achieve them (Appendix B). In order to apply the assessments across the

\footnotetext{
${ }^{1}$ Descriptor 7 (Hydrographical conditions) was not assessed since there has been little clarity on how this aspect of GES should be interpreted.
} 
102 four European regional seas it was often necessary to define several different criteria for each level of 103 risk corresponding with the indicators outlined in the Commission Decision document [9]. Criteria for 104 assessing confidence in the application of the risk score were also developed. Confidence indicates the 105 degree of certainty in our assessment of effort required to achieve GES in each of the four regional 106 seas. These criteria were also of a qualitative nature (e.g. high, medium and low) and were based on 107 the quality of information, the ease of interpreting the information with regards to the assessment 108 criteria and the agreement within the expert group carrying out the assessment (Appendix B).

109 Cardoso et al. [10] also provided information about integrating several different pieces of evidence i.e. 110 whether this should use an integrated or worst case scenario approach. An integrated approach meant 111 that information should be combined before a final assessment was given whilst a worst case 112 approach followed a 'one-out all-out' principle whereby if one set of evidence suggested that the risk 113 was 'high' then 'high' was automatically assessed for the entire descriptor. Descriptors which applied 114 an integrated approach were Biodiversity, NIS, Eutrophication and Seafloor Integrity. All other 115 descriptors used a worst case approach.

\section{$117 \quad 2.3$ Status and pressure assessments}

118 Information required to evaluate GES include descriptions of the status and trends of ecological 119 characteristics in the regional sea, and/or an assessment of the extent and frequency of human 120 pressures and their impacts. The relationship between this evidence and each of the GES descriptors 121 was initially described by Cardoso et al. [10] and here refined to only include direct linkages. These 122 linkages were used to sort available evidence by descriptor therefore specifying which information 123 should be used to assess each descriptor.

125 Status and Trend information

126 Many of the ecological characteristics described in the MSFD are already evaluated in accordance

127 with various Directives, and other national or regional initiatives (e.g. OSPAR). However, these tend 
128 to have different criteria, objectives and baselines, because they fulfil different purposes. Existing 129 status and trend assessments from more than 100 reports, journal articles and grey literature were 130 collated and linked to each ecological characteristic. Where status information was unavailable, trend 131 information was used which describes a change in an indicator over time.

133 Pressures

134 Pressure is the mechanism through which an activity has an effect on any part of the ecosystem, and 135 pressure has been explicitly recognised in some GES descriptors of the MSFD (e.g. Descriptor 10 on 136 Marine Litter and Descriptor 5 on Eutrophication).

137 For those descriptors that require information on pressures, a pressure assessment was used to identify 138 the potential pressure pathways or 'linkages' between activities and ecosystem characteristics followed 139 by evaluation of those linkages in terms of their severity and persistence [11]. Coupled with estimates 140 of human activity footprint (extent) and frequency of occurrence, the relative threat of each activity 141 and pressure to the status of the relevant components of the ecosystem was evaluated. This method 142 uses expert judgment evaluations of five criteria: (1) overlap between the pressure and ecological 143 characteristic (extent), (2) frequency of occurrence of the pressure, (3) degree of impact of the 144 pressure on the ecological characteristic, (4) ecological characteristic resilience (recovery time), and 145 (5) pressure persistence beyond activity cessation. The interaction of each pressure combination was 146 ranked using predefined categories each indicating a different level of threat to the ecological 147 characteristic being evaluated. Information from the results of the pressure assessment undertaken in 148 each regional sea were then used to inform the risk assessment for relevant descriptors.

\section{$150 \quad 2.4 \quad$ The assessment}

151 The assessment was carried out by 30 marine experts from 16 European countries assembled at a 152 workshop in February 2011. Experts were divided into regional groups and assessments were carried 153 out as a team. Biodiversity was disaggregated into five component parts: (1) Phyto-zooplankton, (2) 154 Fish, (3) Seabirds, (4) Marine mammals and reptiles, and (5) Predominant habitat types, due to the 
difficulties associated with an integrated assessment of all those characteristics. Experts used the GES descriptor definitions (Appendix B) and scored the effort required to achieve GES as high, moderate or low using the compiled status and trends database and information from the pressure assessment on their region. For each descriptor, a confidence score was also applied. Where it was not possible to distinguish between 2 risk categories (e.g. low or moderate), an intermediate score was applied e.g. low-moderate. A commentary sheet was also completed during the assessment; this provided a selfassessment framework to ensure consistency of methodology application and interpretation, as well as providing an audit trail for the assessment.

\section{Results}

165 The level of risk in the achievement of GES varied across descriptors and between regions, however when summarized across descriptors, there was little difference in the overall level of risk between regions (Table 1). For the North East Atlantic, six of the 14 descriptor categories were assessed to be at high risk, whilst seven were assessed as high for the other three regions combined. In general pressure based objectives (i.e. underwater noise, marine litter) or those directly related to impacts from pressures (e.g. commercial fish and shellfish and seafloor integrity) exhibited higher risk than

172 Five descriptors were assessed as having a high risk in all four regions (NIS, fish and shellfish, food 173 webs, seafloor integrity and marine litter) (Table 1). Underwater noise was scored as high risk in the 174 NE Atlantic, Mediterranean Sea and Black Sea and moderate-high risk in the Baltic Sea. Only 175 contaminants in fish and shellfish in the Mediterranean Sea was considered at low risk (Table 1).

176 Of the descriptors classified as high risk in all four regions, risk for Commercial Fish and Shellfish 177 was associated with the number of over-exploited species. The Food Web descriptor was at high risk 178 due to declining populations of many of the biodiversity components that form essential parts of the 179 food web (e.g. top predators such as some of the marine mammals) and the poor status of several 180 commercial fish stocks, which both act as a proxy for food web functioning. Seafloor Integrity was 
181 assessed using the results of the pressure assessment and indicated several sectoral activities result in 182 widespread detrimental effects to seafloor habitats and species. In general, increases in the abundance 183 and number of NIS were reported in all regions, and in many cases, evidence of adverse effects 184 shown. The availability of data describing trends in the quantity of Marine Litter was limited, but 185 reports of litter on beaches, the concentration of microplastics in the environment and plastic ingested 186 by seabirds indicated a high risk of failure to achieve our potential GES definitions. Underwater Noise 187 was classified as high risk in three of the four regions; an assessment largely driven by high levels of 188 shipping activity in all regions (see also QSR 2010).

189 The analyses also highlighted some issues specific to each region. For example, Eutrophication was 190 scored as high risk in the Baltic Sea, but classified as moderate risk in all other regions. Both 191 Contaminant descriptors were at higher risk of failing to achieve GES in the Baltic Sea and the Black 192 Sea. There was high risk to Biodiversity in three of the four regional seas. High risk categorisation 193 was achieved when a species/habitat was thought to be of high likelihood to be lost within the next 10 194 years (Table 1) e.g. the critically endangered Monk seal in the Mediterranean Sea[12]. Based on this 195 criterion, high risk Biodiversity sub-groups included marine mammal and reptiles in the 196 Mediterranean, predominant habitats in the Baltic Sea, and seabird diversity in the Black Sea (Table 197 1)

\section{Confidence in assessments}

200 A high degree of confidence was reported for $\sim 40 \%$ of assessments, and $89 \%$ of assessments scored 201 as moderate confidence or better (see confidence criteria in Appendix B). In general, low confidence 202 in assessment was rare in the majority of regions, for example no descriptors in the Baltic and 203 Mediterranean Sea and only Contaminants in Fish and Shellfish in the Black Sea was classified as a 204 low confidence assessment. In contrast, uncertainty in assessments was reported in Biodiversity205 plankton (L-M); Biodiversity-Marine mammals and reptiles (L); Biodiversity-Predominant habitat 206 types; and Contaminants in Fish and Shellfish (L) in the NE Atlantic. 
207 There was more variation in the assessment of confidence between regions than in the assessment of 208 risk itself. For example, the Baltic Sea recorded highest levels of confidence in their assessment (eight 209 out of 14 descriptor categories were recorded as high confidence whilst the other regions only 210 allocated high confidence to five out of 14 descriptor categories). In general, the confidence in 211 assessment of descriptors Eutrophication, Seafloor Integrity and Contaminants was high. However, 212 there were only three descriptors (Marine litter, Biodiversity-predominant habitat types and 213 Biodiversity- marine mammals) which differed by more than one whole confidence score between 214 regions (i.e. low in one region and high in another). Less than half of assessments (41\%) were given 215 both a high risk and a high confidence score (i.e. 11 assessments out of 27 total assessments scored as 216 high risk and high confidence). Only three assessments in total were considered to have a low 217 confidence and none of these was considered to have high risk of failure.

\section{Discussion}

220 The Marine Strategy Framework Directive (MSFD) is the first piece of legislation applied across

221 Europe's regional seas that requires assessment of the range of issues that should encompass overall 222 marine environmental sustainability [13]. Prior to this coming into place, legislation tended to focus 223 primarily on a single activity or issue. As such, most status, trend and impact assessments also 224 focused on these specific issues. Broader assessments of the status of marine ecosystems do exist for 225 particular sea areas (e.g. under the regional sea conventions), but although their focus may in some 226 cases align with the MSFD's overall objective of healthy, productive, safe and biologically diverse 227 seas, the reporting does not tend to cover all aspects of GES (the 11 GES descriptors) (Appendix A).

228 We have presented a methodology that combines information on status and human impacts within a 229 regionally consistent framework to assess the level of risk to GES. Over 100 sources were included in 230 the risk analysis and included broad-scale assessments of status (e.g. [14]), pressure distribution (e.g. 231 [15]), impacts (e.g.[16]) and trends in ecosystem characteristics (e.g. [17]). Sources covered a range 
232 of assessment timelines, reference conditions and were of varying spatial coverage. However, in the 233 majority of cases, the regional expert groups felt confident and could agree on a suitable risk category.

234 The need for such a methodology was highlighted in the process of conducting the assessments, when 235 specific national or sub-regional status reports were inconsistent with overall regional views. For 236 example, UK predominant habitats [14] are reported as being in poor status, but when assessing risk 237 to GES based on Biodiversity of predominant habitats for the whole regional sea (in this case the NE 238 Atlantic), the level of risk was classified as 'moderate' (see Figure 1) indicating the importance of 239 considering spatial scale of assessments when evaluating status at a regional sea level.

240 The assessment of risk of failing to achieve these GES definitions identified issues for regional 241 prioritization in addition to those identified in existing status reports. For example, the Baltic Sea and 242 Black Sea Action Plans [18] [19] focus on issues relating to the descriptors (1) Biodiversity, (5) 243 Eutrophication, (6) Seafloor Integrity and (8\&9) Contaminants and Contaminants in Fish and 244 Shellfish. However, the risk assessment undertaken here suggests that NIS, Food Webs, Marine Litter 245 and Underwater Noise are also potential areas of concern. This shows that translation of the outcomes 246 of even spatially comparable assessments and their placement in the context of the MSFD may be 247 precluded by differences in assessment objectives.

\section{Levels of risk to achieving GES}

250 Application of the risk methodology to Europe's four regional seas identified GES descriptors at high 251 risk that were common to all regional seas, suggesting a similar level of effort required within all 252 regions to achieve the MSFD objectives. In most cases, the contributing threats to the high risk 253 classification were logical and fit well with documented areas of concern e.g. commercial fish 254 sustainability, the establishment and spread of NIS, amount of marine litter, the state of food webs and 255 the extent of human activities. Similarly, descriptors classified as at moderate or low risk, such as 256 Contaminants and Eutrophication, are already focus issues of regional sea conventions and in some 257 cases, have been regulated for many years. 
258 Surprisingly, there were few high risk Biodiversity components, despite some other descriptors that 259 we might expect to have consequences for Biodiversity such as NIS classified as at high risk. Risk 260 outcomes are closely linked to the level of ambition of the descriptor and these differed between the 261 descriptors. Using the example of NIS and Biodiversity, the crucial difference in GES ambition is in 262 the definition of acceptable 'loss'. High risk under Biodiversity requires the likelihood of "loss of 263 biodiversity or maintained change in dominance/assemblage structure" (Appendix B) (both of which 264 are major changes at a regional sea scale), whereas for NIS, significant adverse effects of an invasive 265 species do not have to be as severe as elimination of a population and can include effects such as 266 increased seasonal dominance of algal blooms in the region.

267 Disparities may also be the result of the level of precaution adopted. The timeline for biodiversity loss 268 was defined as $<10$ years (i.e. within the 2020 reporting timescale of the MSFD). However, this 269 timeline is perhaps not precautionary enough to help prioritise management. For example, a species or 270 habitat faced with loss from an area as large as one of Europe's regional seas within the next 10 years 271 may be beyond recovery [20] and therefore, high risk criteria should reflect a period before the 272 condition/status of the habitats/species becomes irrecoverable. Doing so would potentially result in a 273 high risk score for a greater number of biodiversity components.

274 Difficulties in assessing risk criteria may also account for differences in risk score. The availability of 275 reliable information on threatened and declining species or changes in dominance of assemblages (the 276 two types of criteria for biodiversity) can vary widely and thus, affect the outcome of the assessment. 277 Confidence in assessment can be interpreted in terms of prioritization of action to help achieve GES 278 for particular descriptors where there are data or an understanding of the limitations of the data. As 279 such, when confidence is low or low-moderate, recommended actions might include: (i) implementing 280 monitoring programmes to improve data knowledge, (ii) re-analysing data to make our current data 281 more useful for the MSFD, (iii) further development and research to improve understanding and use 282 of the descriptors. 
283 Where improving data provision is not possible, it may be more sensible to use a precautionary

284 approach whereby high risk in one descriptor (e.g. Seafloor Integrity) automatically triggers high risk 285 categorisation of a related descriptor i.e. Biodiversity of predominant habitats. This would ensure that 286 at a minimum, monitoring and evaluation of biodiversity aspects would occur. There are clear inter287 relationships between some of the descriptors of Europe's MSFD [5] and our results suggest that it 288 will be important to recognise the links between descriptors such that high risk issues identified for 289 one descriptor can trigger a similarly high level of priority in others.

\section{Implications for prioritisation of management and monitoring}

292 Given the high number of high risk issues for GES in each of Europe's regional seas as illustrated 293 here, it is clear that member states (MSs) will need to implement management measures for many of 294 the descriptors by 2016. A number of MSs are reviewing the types and performance of existing 295 management measures and mapping the suitability of these in tackling areas of concern. For some 296 descriptors, existing measures may already be helping to reduce the likelihood of status deteriorating 297 beyond GES thresholds. Depending on the spatial scale of those measures e.g. national vs. regional 298 programmes, dialogue between MSs could support the objectives of existing management options and 299 also address the collaborative requirement of the MSFD (Article 13). However, the complexity in 300 achieving GES at a regional sea scale should not be underestimated and may limit potential 301 collaboration [21]. For example, for some regional seas the proportion of countries bordering the sea 302 that are MSs (and obligated under the MSFD) is low and/or in other cases, the natural conditions 303 within a region may require targets for GES that are less ambitious.

304 For other descriptors (e.g. NIS, Commercial Fish and Shellfish, Marine Litter) existing measures are 305 clearly not sufficient in any of Europe's regional seas. The recent consultation on the Common 306 Fisheries Policy [22] (CFP) reflects the widespread understanding that fisheries management in 307 Europe must change if we are to support sustainable fisheries. Irrespective of the level of 308 implementation, it is likely that MSs will still be required to assess their own stocks and need to 
309 reduce the number of species that are overexploited. Measures required to improve status will

310 certainly require international coordination and agreements to be effective. For example, the

311 Convention on Biological Diversity (CBD) has recently provided guidance for some descriptors, such

312 as NIS by the major sources and pathways of introduction and suggesting that stricter reduction

313 measures should be introduced [23].

315 Conclusions

316 Key elements of the MSFD include the need for a knowledge-based approach driven initially by what 317 we already know [24] and the need for co-ordinated efforts within and between regional seas [4, 5, 8, 318 9]. Given the current global economic downturn it is likely that MSs will first look to existing data 319 gathering exercises to support the MSFD. This is reflected in the approach taken by several member 320 states (e.g. UK, Germany, Netherlands) who have begun to develop targets and indicators based on 321 outcomes of existing monitoring programmes and regional assessments [25]. The results presented 322 here are a first attempt to take the existing status and trends assessments to assess risk to GES using a 323 transparent and consistent risk based approach. Our experience of applying this approach across 324 Europe's regional seas supports the need for a common tool if the results from the initial assessments 325 are to be in any way comparable.

326 This first look at regional priorities identified five high risk issues common across regional seas, and 327 several other areas where there is high risk in particular regional seas. This supports existing 328 suggestions that joined up, cross regional work on the development of objectives, targets, monitoring 329 programmes and management should be undertaken [5]. High risk outcomes also provide an initial 330 prioritization of management measures and in association with tools such as Management Strategy 331 Evaluation (MSE; e.g. [26]) and Cost Benefit Analysis (CBA; e.g. [27]), measures that confer the 332 greatest benefits in terms of environmental, socio-cultural and economic status can be identified. Our 333 analyses suggest the need for a pragmatic approach which links descriptors so that the introduction of 
management measures could lead to multiple gains in terms of the environmental, social and

economic benefits while increasing the likelihood of GES being achieved in Europe's regional seas.

Acknowledgements

This work is funded by and is part of the ongoing research within the EU FP7 programme 'Options

for Delivering Ecosystem Based Marine Management’ (ODEMM; grant number: 244273;

www.liv.ac.uk/odemm). Matched funds are provided to Cefas by DEFRA project number E5405.

\section{References}

[1] Curtin R, Prellezo R. Understanding marine ecosystem based management: A literature review. 344 Marine Policy. 2010;34:821-30.

[2] Rosenberg A, Sandifer P. What do Managers Need? Ecosystem-Based Management for the Oceans. Washington DC: Island Press; 2009.

[3] Ruckelshaus M, Klinger T, Knowlton N, DeMaster DP. Marine Ecosystem-based Management in Practice: Scientific and Governance Challenges. BioScience. 2008;58:53-63. [4] EC. DIRECTIVE 2008/56/EC OF THE EUROPEAN PARLIAMENT AND OF THE COUNCIL of 17 June 2008 establishing a framework for community action in the field of marine environmental policy (Marine Strategy Framework Directive). 2008.

[5] Borja A, Elliott M, Carstensen J, Heiskanen AS, van de Bund W. Marine management - Towards an integrated implementation of the European Marine Strategy Framework and the Water Framework Directives. Marine Pollution Bulletin. 2010;60:2175-86.

[6] Foden J, Rogers SI, Jones AP. A critical review of approaches to aquatic environmental assessment. Marine Pollution Bulletin. 2008;56:1825-33.

[7] OSPAR. Quality Status Report 2010. London OSPAR Commission; 2010.

[8] Piha H, Zampoukas N. Review of Methodological Standards Related to the Marine Strategy Framework Directive Criteria on Good Environmental Status. European Commission Joint Research Centre. Institute for Environment and Sustainability; 2010.

[9] EC. Commission Decision of 1 September 2010 on criteria and methodological standards on good environmental status of marine waters. Brussels: European Commission 2010/477/EU; 2010.

[10] Cardoso AC, Cochrane S, Doerner H, Ferreira JG, Galgani F, Hagebro C, et al. SCIENTIFIC SUPPORT TO THE EUROPEAN COMMISSION ON THE MARINE STRATEGY FRAMEWORK DIRECTIVE Management Group Report. 2010.

[11] Robinson LA, Rogers SI, Frid CLJ. A marine assessment and monitoring framework for application by UKMMAS and OSPAR - Assessment of Pressures. Contract No: F90-01-1075 for the Joint Nature Conservation Committee: University of Liverpool, Liverpool and Centre for the Environment, Fisheries and Aquaculture Science, Lowestoft; 2008. p. 108.

[12] IUCN. The IUCN Red List of Threatened Species. 2011.

[13] EC. Directive 2008/56/EC of the European Parliament and of the Council of 17 June 2008 establishing a ramework for community action in the field of marine environmental policy (Marine Strategy Framework Directive). Official Journal of the European Union2008. p. 19-40.

[14] DEFRA. Charting Progress 2: The state of UK Seas. London DEFRA; 2010. p. pp. 194. 
375 [15] BSC. Marine Litter in the Black Sea Region. Istanbul: Black Sea Commission; 2009.

376 [16] DAISIE. Handbook of Alien Species in Europe2009.

377 [17] Greenstreet SPR, Rogers SI. Indicators of the health of the North Sea fish community:

378 identifying reference levels for an ecosystem approach to management. ICES Journal of Marine

379 Science: Journal du Conseil. 2006;63:573-93.

380 [18] BSC. Strategic Action Plan for the Environmental Protection and Rehabilitation of the Black Sea. 381 Sofia: Black Sea Commission; 2009.

382 [19] HELCOM. HELCOM Baltic Sea Action Plan. Krakow: HELCOM; 2007.

383 [20] IUCN. IUCN Red List Categories and Criteria version 3.1. IUCN; 2001. p. ii +30 pp.

$384 \quad$ [21] Koss R. in prep.

385 [22] EC. European Commission: a fisheries policy for the future In: Commission E, editor.2011.

386 [23] CBD. Aichi Biodiversity Targets. 2011.

387 [24] Borja A. The new European Marine Strategy Directive: Difficulties, opportunities, and 388 challenges. Marine Pollution Bulletin. 2006;52:239-42.

389 [25] ICES.WGECO. Unpublished report. 2011.

390 [26] Punt A, \#233, E., Smith ADM, Cui G. Evaluation of management tools for Australia\&apos;s

391 South East Fishery. $<\mathrm{BR} />3$. Towards selecting appropriate harvest strategies. Marine and Freshwater 392 Research. 2002;53:645-60.

393 [27] Pearce D. Cost-benefit analysis and environmental policy. Oxford review of economic policy. 394 1998;14:84-100. 

.

Table 1. Results of the risk assessment for each descriptor per regional sea. Darker grey colour

399 indicates high risk whilst a lighter grey indicates a lower risk. High risk/confidence was scored 3,

400 moderate risk 2 and low risk 1 . Total indicated the overall risk in assessments per region across

401 descriptors and per descriptor across all regions.

\begin{tabular}{|c|c|c|c|c|c|}
\hline & NEA & MED & Baltic & Black & $\begin{array}{l}\text { Total } \\
\text { across } \\
\text { regions }\end{array}$ \\
\hline Biodiversity-Phyto-zooplankton & LM & $\mathrm{M}$ & M & $\mathrm{M}$ & 7.5 \\
\hline Biodiversity-Fish & $\mathrm{M}$ & $\mathrm{M}$ & M & $\mathrm{M}$ & 8 \\
\hline Biodiversity-Marine mammals and reptiles & LM & $\mathrm{H}$ & M & MH & 9 \\
\hline Biodiversity-Seabirds & $\mathrm{M}$ & $\mathrm{M}$ & $\mathrm{M}$ & $\mathrm{H}$ & 9 \\
\hline Biodiversity-Predominant habitat types & $\mathrm{M}$ & $\mathrm{M}$ & $\mathrm{H}$ & $\mathrm{MH}$ & 9.5 \\
\hline Non-indigenous species & $\mathrm{H}$ & $\mathrm{H}$ & $\mathrm{H}$ & $\mathrm{H}$ & 12 \\
\hline Fish and shellfish & $\mathrm{H}$ & $\mathrm{H}$ & $\mathrm{H}$ & $\mathrm{H}$ & 12 \\
\hline Food webs & $\mathrm{H}$ & $\mathrm{H}$ & $\mathrm{H}$ & $\mathrm{H}$ & 12 \\
\hline Eutrophication & $\mathrm{M}$ & $\mathrm{M}$ & $\mathrm{H}$ & $\mathrm{M}$ & 9 \\
\hline Sea floor integrity & $\mathrm{H}$ & $\mathrm{H}$ & $\mathrm{H}$ & $\mathrm{H}$ & 12 \\
\hline Contaminants & $\mathrm{M}$ & M & MH & MH & 9 \\
\hline Contaminants in fish and shellfish & LM & $\mathrm{L}$ & $\mathrm{M}$ & $\mathrm{M}$ & 6.5 \\
\hline Marine litter & $\mathrm{H}$ & $\mathrm{H}$ & $\mathrm{H}$ & $\mathrm{H}$ & 12 \\
\hline Underwater noise & $\mathrm{H}$ & $\mathrm{H}$ & $\mathrm{MH}$ & $\mathrm{H}$ & 11.5 \\
\hline Total score & 32.5 & 34 & 36 & 36.5 & \\
\hline
\end{tabular}

\section{Risk}

High $\mathrm{H}$

Moderate-high

Moderate $\mathrm{MH}$

Low-moderate $\mathrm{M}$

Low

LM 
403 Table 2. Results of the confidence assessment for each descriptor per regional sea. Darker grey colour 404 indicates higher confidence in the risk assessment whilst a lighter grey colour indicates a lower 405 confidence in the risk assessment.

\begin{tabular}{lllll}
\hline & NEA & MED & Baltic & Black \\
\hline Biodiversity-Phyto-zooplankton & LM & M & M & M \\
\cline { 2 - 5 } Biodiversity-Fish & MH & M & H & M \\
\cline { 2 - 5 } $\begin{array}{l}\text { Biodiversity-Marine mammals and reptiles } \\
\text { Biodiversity-Seabirds }\end{array}$ & L & H & H & H \\
\cline { 2 - 5 } Biodiversity-Predominant habitat types & M & M & H & H \\
\cline { 2 - 5 } Non-indigenous species & L & M & H & M \\
\cline { 2 - 5 } Fish and shellfish & MH & H & H & H \\
\cline { 2 - 5 } Food webs & H & M & MH & M \\
\cline { 2 - 5 } $\begin{array}{l}\text { Eutrophication } \\
\text { Sea floor integrity } \\
\text { Contaminants }\end{array}$ & M & M & H & M \\
\cline { 2 - 5 } Contaminants in fish and shellfish & M & M & H & H \\
\cline { 2 - 5 } $\begin{array}{l}\text { Marine litter } \\
\text { Underwater noise }\end{array}$ & H & H & H & H \\
\hline
\end{tabular}

\section{Confidence}

$\begin{array}{ll}\text { High } & \mathrm{H} \\ \text { Moderate-high } & \mathrm{MH} \\ \text { Moderate } & \mathrm{M} \\ \text { Low-moderate } & \text { LM } \\ \text { Low } & \text { L }\end{array}$


$407 \quad$ Figure 1

408 Figure 1. The four European regional seas included in the Marine Strategy Framework Directive. 


\section{Appendix A}

410 Descriptor 1. Biological diversity is maintained. The quality and occurrence of habitats and the

411 distribution and abundance of species are in line with prevailing physiographic, geographic and

412 climatic conditions. (Biodiversity)

413 Descriptor 2. Non-indigenous species introduced by human activities are at levels that do not

414 adversely alter the ecosystems. (Non-Indigenous Species)

415 Descriptor 3. Populations of all commercially exploited fish and shellfish are within safe

416 biological limits, exhibiting a population age and size distribution that is indicative of a healthy stock.

417 (Fish and Shellfish)

418 Descriptor 4. All elements of the marine food webs, to the extent that they are known, occur at 419 normal abundance and diversity and levels capable of ensuring the long-term abundance of the 420 species and the retention of their full reproductive capacity. (Food Webs)

421 Descriptor 5. Human-induced eutrophication is minimised, especially adverse effects thereof, such 422 as losses in biodiversity, ecosystem degradation, harmful algae blooms and oxygen deficiency in 423 bottom waters. (Eutrophication)

424 Descriptor 6. Sea-floor integrity is at a level that ensures that the structure and functions of the 425 ecosystems are safeguarded and benthic ecosystems, in particular, are not adversely affected. (Sea426 floor integrity)

427 Descriptor 7. Permanent alteration of hydrographical conditions does not adversely affect marine 428 ecosystems. (Hydrographical Conditions)

429 Descriptor 8. Concentrations of contaminants are at levels not giving rise to pollution effects.

430 (Contaminants)

431 Descriptor 9. Contaminants in fish and other seafood for human consumption do not exceed levels 432 established by Community legislation or other relevant standards. (Contaminants in Fish and 433 Shellfish)

434 Descriptor 10. Properties and quantities of marine litter do not cause harm to the coastal and marine 435 environment. (Marine Litter) 
436 Descriptor 11. Introduction of energy, including underwater noise, is at levels that do not adversely 437 affect the marine environment. (Underwater Noise) 


\section{Descriptor 1: Biodiversity}

Good status is achieved when biodiversity is maintained in the regional sea such that the quality and occurrence of habitats and the distribution and abundance of species are in line with prevailing physiographic, geographic and climatic conditions. Failure of GES is defined to occur where there is loss of biodiversity beyond that expected under prevailing conditions before 2020. Loss of 44 biodiversity can be described as occurring where there is a reduction in genetic, species, habitat or 45 ecosystem diversity within the regional sea over this time scale. More specifically loss of particular meta-populations, species, habitat types or ecosystem properties within the region (e.g. extirpations) 447 would certainly count as a loss of biodiversity, but so could a noticeable change in diversity based on 448 changes in evenness (e.g. shifts in dominance). However, both of these cases would need to be a 449 loss/change beyond that expected under prevailing conditions. GES under Biodiversity should be 450 assessed individually for each of the major ecosystem characteristics listed in Annex iii of the MSFD 451 as recommended in the Commission decision. Consideration should be given separately to listed 452 species and habitats under the Habitats Directive. Consistency should be checked against the level of 453 risk identified for other relevant Descriptors (e.g. seafloor integrity for the aspects of habitats454 ecosystem level diversity).

55 Table B.1 Risk categories for Biodiversity

\begin{tabular}{|c|c|}
\hline \multirow[t]{3}{*}{ High (3) } & $\begin{array}{l}\text { Continued decline in a genotype, species, habitat or ecosystem type at } \\
\text { the regional scale (decline in biodiversity) to the extent that there is a } \\
\text { high likelihood of its loss from the region (= extirpation)within the next } \\
10 \text { years }\end{array}$ \\
\hline & and/or \\
\hline & $\begin{array}{l}\text { Maintained change in the dominance of genotypes, species, habitat types } \\
\text { or ecosystem types (change in evenness) where this change is likely to } \\
\text { last for at least the next } 10 \text { years }\end{array}$ \\
\hline Moderate (2) & $\begin{array}{l}\text { New or further decline in extent and/or condition of genotypes, species, } \\
\text { habitat types or ecosystem types at the regional scale within the next } 10 \\
\text { years }\end{array}$ \\
\hline & and/or \\
\hline
\end{tabular}


Alterations in the dominance of genotypes, species, habitat types or ecosystem types (change in evenness) within the next 10 years, not necessarily having led to a maintained change

Low (1) No notable changes in extent and condition of genotypes, species, habitat types or ecosystems at the scale of the region beyond that expected given prevailing conditions within the next 10 years

and

No clear change in dominance of genotypes, species, habitat types or ecosystem types (change in evenness) given prevailing conditions within the next 10 years

457 Descriptor 2: Non-indigenous species introduced by man

458 GES for Non-indigenous species (NIS) is a function of their relative abundances and distribution

459 ranges, and environmental impact. These may vary from low abundances in one locality with no

460 measurable adverse effects, up to occurrence in high numbers in many localities resulting in

461 significant impacts. Good status will be maintained when significant adverse effects on

462 environmental quality from NIS are avoided, including no elimination or extinction of sensitive

$463 \mathrm{and} /$ or rare populations, alteration of native communities, seasonal dominance of algal blooms,

464 alteration of water chemistry (oxygen, nutrient content, $\mathrm{pH}$ and transparency) or accumulation of

465 synthetic pollutants. Invasive NIS are a subset of established NIS which have spread, are spreading or

466 have demonstrated their potential to spread elsewhere and have an adverse effect on environmental

467 quality. Therefore it is invasive NIS that are of most concern in terms of posing a risk to GES.

468 Table B.2 Risk categories for NIS
High abundance and increasing trends in abundance of established invasive NIS in many sub-regions

and/or

High numbers of invasive NIS in many sub-regions.

and

Clear evidence of significant adverse effects on environmental quality in those sub-regions 
Moderate (2) High abundance of some established invasive NIS in some sub-regions or generally increasing trends in abundance in some areas.

and/or

High numbers of invasive NIS in some sub-regions

and

Evidence of adverse effects at species, habitat or ecosystem level but only in some sub regions

Low (1) Low abundance of established invasive NIS in the region with no apparent increasing trends.

and/or

Low numbers of invasive NIS

and

No evidence of adverse effects at species, habitat or ecosystem level
469

470 Descriptor 3: Commercial Fish and shellfish

471 GES for commercially exploited fish and shellfish will be achieved when stocks are sustainably

472 exploited consistently with high long-term yields and have full reproductive capacity. To achieve

473 GES it will also be necessary, in addition to sustainably exploited stocks at full reproductive capacity,

474 for the age and size distribution of fish and shellfish populations to be representative of a healthy

475 stock, assessed by reference to the proportion of older and larger fish in the population. GES is

476 achieved for a particular stock only if criteria for all attributes are fulfilled.

477 Table B.3 Risk categories for commercially exploited fish and shellfish

High (3) $\quad \begin{aligned} & \text { SSB }<\text { SSBpa for some stocks } \\ & \text { and/or } \\ & \text { exploitation rate F exceeds precautionary levels for some }(>25 \%) \text { stocks } \\ & \text { and/or } \\ & \text { the age and size distribution of fish and shellfish stocks shows } \\ & \text { consistent long-term degradation. i.e. smaller, younger fish. }\end{aligned}$




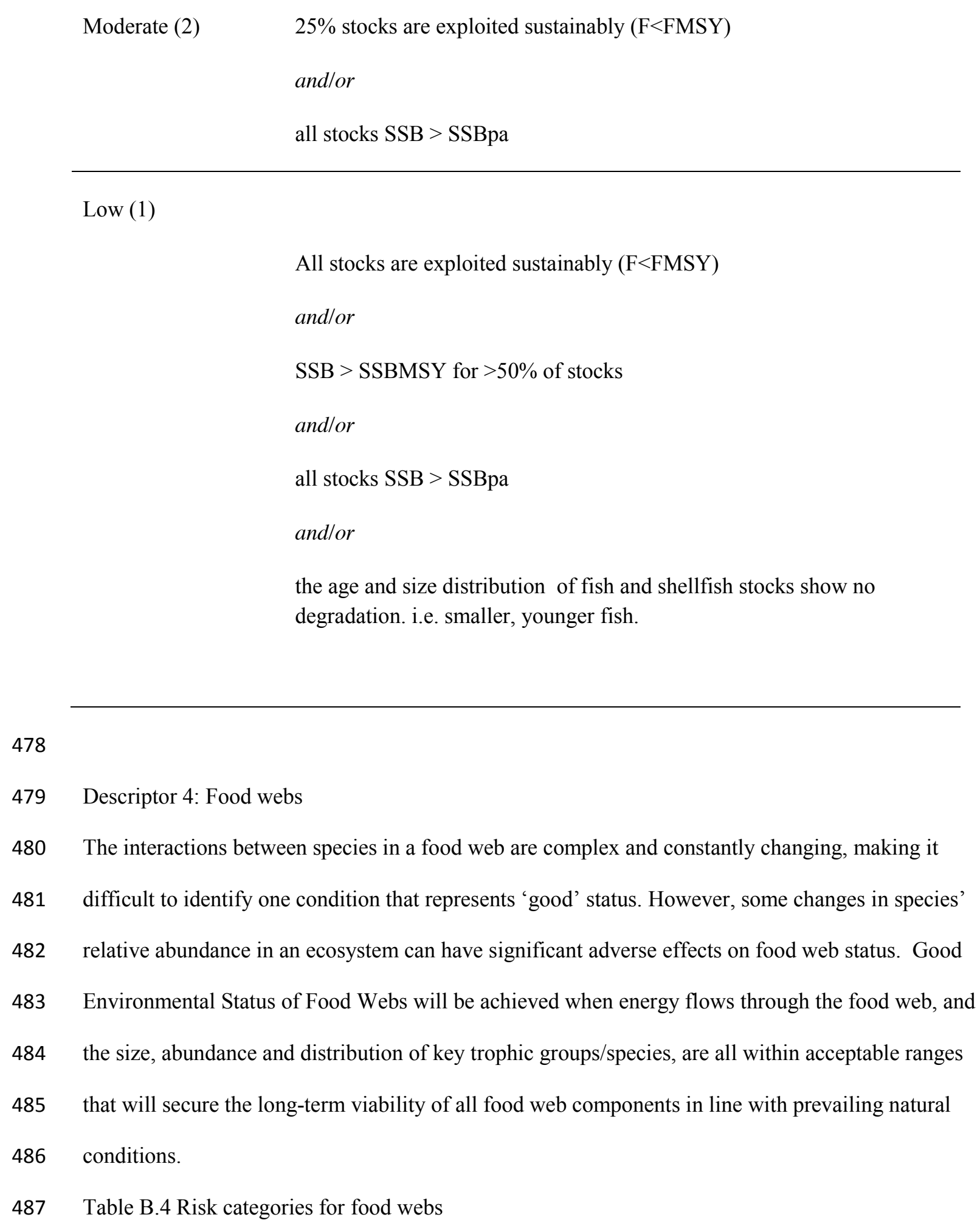

Low (1)

High (3)

Spatially extensive and long-term changes have occurred in energy flows 
through the food web, as recorded by changes in the productivity (production per unit biomass) of several key species or trophic groups, which have both direct and indirect effects on different trophic levels.

and/or

Trends in the abundance and distribution of carefully selected indicator populations, and in the proportion of species at the top of food webs, show continuous decline across the Region and provide evidence of adverse impacts on food web integrity.

Moderate (2) Recent changes in the productivity (production per unit biomass) of some key species or trophic groups suggest that direct and indirect effects have occurred on different trophic levels.

and/or

Trends in the abundance and distribution of local indicator populations, and in the proportion of species at the top of food webs, suggest that adverse impacts to food web structure have occurred in some subregions.

Low (1) Recorded changes in energy flows through the food web, as recorded by changes in the productivity (production per unit biomass) of key species or trophic groups, have no significant direct and indirect effects on different trophic levels.

and/or

Trends in the abundance and distribution of carefully selected indicator populations, and in the proportion of species at the top of food webs, vary in accordance with natural cycles and show no cause for concern in relation to food web structure.

489 Descriptor 5: Eutrophication

490 GES with regard to eutrophication has been achieved when the biological community remains

491 well-balanced and retains all necessary functions in the absence of undesirable disturbance associated

492 with eutrophication (e.g. excessive harmful algal blooms, low dissolved oxygen, declines in

493 seagrasses, kills of benthic organisms and/or fish) and/or where there are no nutrient-related impacts

494 on sustainable use of ecosystem goods and services. 
Table B.5 Risk categories for Eutrophication

High (3) Undesirable disturbance* caused by eutrophication is widespread (even or patchy) and frequent in the region ( $>$ once a year)

Moderate (2) Undesirable disturbance* caused by eutrophication is widespread but rare in the region $(<$ once a year $)$

And/or

Undesirable disturbance* caused by eutrophication only occurs at a site or local scale in the region, but it occurs at least once a year

Low (1) Undesirable disturbance* caused by eutrophication does not occur in the region, or where it does occur it only occurs rarely (<once a year) and on a very local scale (site or local patchy)

$498 *$ Undesirable disturbance includes one or more of the following: harmful algal blooms, low dissolved 499 oxygen, associated declines in perennial seaweeds or seagrasses, kills of benthos and fish, dominance 500 by opportunistic macroalgae

502 Descriptor 6: Sea-floor integrity

503 GES is achieved where seafloor integrity is at a level that ensures that the structures and functions of 504 the ecosystems are safeguarded and benthic ecosystems, in particular, are not adversely affected. "Sea 505 Floor" includes both the physical structure and biotic composition of the benthic community.

506 "Integrity" includes the characteristic functioning of natural ecosystem processes and spatial 507 connectedness. "Not adversely affected" is interpreted as meaning that impacts may be occurring, but 508 at a level where natural levels of diversity, productivity, and dynamic ecosystem processes are not 509 degraded

510 Seafloor integrity will be assessed here for the broad predominant habitat types only where the 511 assessment will be based on the outcomes of the pressure assessment undertaken in ODEMM and any 512 other useful information on status/trends at the broad habitat level. Thus the integrity of the seafloor is 
513 assessed in terms of the extent of damage caused by the various human activities that interact with it.

514 This is done indirectly through a pressure assessment.

515 The habitats listed under the Habitats Directive will be assessed against the FCS criteria of the

516 Habitats Directive (listed after the MSFD descriptors). If they are achieving FCS they will also be

517 meeting the criteria for GES for seafloor integrity. If they are failing against the FCS criteria that in

518 itself identifies a regional mismatch to the relevant HLO.

519 Table B.6 Risk categories for Sea-floor integrity

High (3) Where the pressures and habitats overlap:

1. Extent is widespread (even or patchy), severity is acute or chronic and the persistence of the pressure is high or continuous, irrespective of frequency of occurrence

and/or

2. Extent is widespread (even or patchy), severity is acute and the frequency of occurrence is occasional or higher, irrespective of Persistence category

and/or

3. Extent is widespread (even or patchy), severity is chronic and the frequency is persistent or common, irrespective of Persistence category

and/or

4. A combination of multiple local pressures which result in a widespread extent with a severity, frequency and persistence combination equivalent to one of the above

and/or

5. The overlap of multiple low severity pressures which combine to form a severe (acute or chronic) impact combination equivalent to one of the above

Moderate (2) Any combination other than high or low

Low (1) Where severity is classified as 'low' for all interactions with pressures in the region even when they are combined

and/or 
Where any severe effects (chronic or acute) occur and frequency of occurrence is rare, persistence of the pressure is low, and resilience of the habitat is high

521 Descriptor 8: Contaminants in the environment

522 Assessment of whether concentrations of contaminants are at levels not giving rise to pollution effects

523 should be based on monitoring programmes for chemical contaminants, and on biological

524 measurements relating to the effects of pollutants on marine organisms in each of the assessment

525 regions. GES will therefore be achieved when concentrations of contaminants in water, sediment and

526 biota are below assessment thresholds identified on the basis of toxicological data; pollution levels are

527 below assessment thresholds representing harm at organism, population, community and ecosystem

528 levels; and trends in concentrations of contaminants in water, sediment and biota, and the occurrence

529 and severity of pollution effects, are within acceptable limits and declining.

530

531 Table B.7 Risk categories for contaminants in the environment

High (3) Concentrations of all contaminants in biota, sediments and water exceed the relevant Environmental Quality Standards over extensive areas of the Region.

and/or

Significant impacts on and risk to the marine environment have recently been shown by the occurrence and extent of pollution effects throughout the Region.

Moderate (2) Concentrations of some contaminants in biota, sediments and water exceed the relevant Environmental Quality Standards in some subregions of the Region.

and/or

Impacts on and risk to the marine environment have recently been shown by the occurrence and extent of pollution effects in sub-regions.

Low (1) Concentrations of contaminants in biota, sediments and water do not exceed the relevant Environmental Quality Standards established for the 


\section{Region.}

and/or

The occurrence and extent of pollution effects throughout the Region indicate no significant impacts on or risk to the marine environment

533 Descriptor 9: Contaminants in fish and shellfish

534 A number of contaminants in the marine environment giving rise to concern both from an

535 environmental and public health point of view have been selected. Regulatory levels have been laid 536 down for lead, cadmium, mercury, polycyclic aromatic hydrocarbons, dioxins \& dioxin-like PCBs 537 and radionuclides. Other substances of concern are arsenic, non-dioxin like PCBs, phthalates, 538 organochlorine pesticides, organotin compounds, brominated flame retardants and polyfluorinated 539 compounds. Good Environmental Status (GES) would be achieved if all contaminants are at levels 540 below the levels established for human consumption or showing a downward trend (for the substances 541 for which monitoring is ongoing but for which levels have not yet been set). However, it is generally 542 felt that GES for descriptor 9 must be judged in view of the monitoring of descriptor 8, also dealing 543 with contaminants in the marine environment.

544 Table B.8 Risk categories for contaminants in fish and shellfish

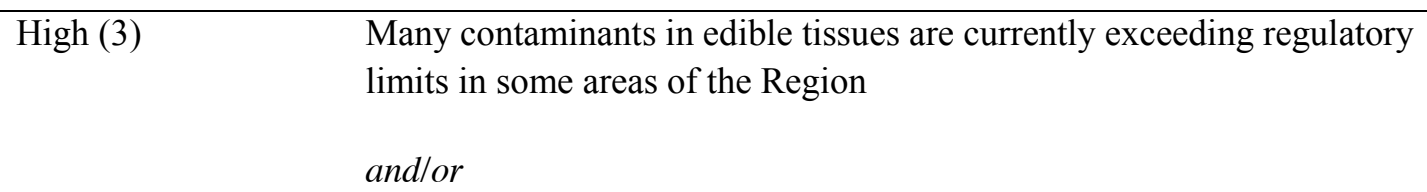

Regulatory levels of one or more contaminants in edible tissues are being exceeded on a regular basis in large areas of the Region.

\begin{tabular}{ll}
\hline Moderate (2) & $\begin{array}{l}\text { Some contaminants in edible tissues are currently exceeding regulatory } \\
\text { limits in some areas of the Region. }\end{array}$ \\
& $\begin{array}{l}\text { and/or } \\
\text { Regulatory levels of one or more contaminants in edible tissues are } \\
\text { being exceeded occasionally in large areas of the Region. }\end{array}$ \\
\hline Low (1) & $\begin{array}{l}\text { Levels of contaminants in edible tissues do not currently exceed } \\
\text { regulatory limits anywhere in the Region. }\end{array}$
\end{tabular}


or

Regulatory levels are rarely exceeded in large areas of the Region.

546 Descriptor 10: Marine litter

547 GES occurs when the properties and quantities of marine litter do not cause harm to the coastal and

548 marine environment. This can be achieved through a measurable and significant decrease in

549 comparison with the baseline (i.e. the situation up until 2012) in the total amount of marine litter by

5502020 using as attributes the characteristics of litter in the marine and coastal environment and the

551 impacts of litter on marine life. In addition, it is possible to use information from the ODEMM

552 pressure assessments on the the intertidal habitats for criterion 1 and the pelagic water column habitat

553 for criterion 2 in all risk categories below. The information in the pressure assessment can be used to

554 summarise the spatial extent and frequency of any activities adding marine litter to the environment,

555 since marine litter is one of the pressure categories used. Any additional information on the future

556 trends in activity for the major sectors contributing litter can also be used to ascertain whether the

557 extent of marine litter currently recorded in the pressure assessment is likely to change in the future.

558 Table B.9 Risk categories from Marine Litter

High (3) Unchanged or increasing trend in the amount of litter washed ashore and / or deposited on coastlines over widespread areas (patchy distribution within this fine) of the region.

and/or

Unchanged or increasing trend in the amount of litter in the water column over widespread areas of the region.

and/or

Unchanged or increasing trend of micro particles over widespread areas of the region

and/or

Unchanged or increasing trend in litter ingested by large numbers of marine 
animals in the region
Moderate (2) Unchanged or increasing trend in the amount of litter washed ashore and / or deposited at coastlines in some sub-regions
and/or

Unchanged or increasing trend in the amount of litter in the water column in some sub regions

and/or

Unchanged or increasing trend of micro particles in some sub regions

and/or

Unchanged or increasing trend in litter ingested by marine animals in some sub regions

Low (1) Decreasing trend in the amount of litter washed ashore and / or deposited at coastlines over extensive areas of the region

and/or

Decreasing trend in the amount of litter in the water column over extensive areas of the region.

and/or

Decreasing trend of micro particles over extensive area of the region.

and/or

Decreasing trend in litter ingested by marine animals over extensive areas of the region.

560 Descriptor 11: Underwater noise

561 In relation to underwater noise, GES would occur when there is no adverse effect of noise inputs on

562 any component of the environment. However such an objective is probably not achievable or

563 measurable. Therefore indicators for environmental status have been developed that are based on

564 pressures addressing two main issues with regards to underwater noise. One is the distribution in time 565 and place of loud, low and mid frequency impulsive sound that is mainly introduced by offshore 
566 construction using pile driving (e.g. for offshore wind farms) and seismic surveys. The other is the

567 trend of continuous low frequency sound indicated mainly by shipping activity.

568 Table B.10 Risk categories for underwater noise

\begin{tabular}{ll}
\hline High (3) & $\begin{array}{l}\text { High activity and increasing trend of offshore construction using pile } \\
\text { driving (e.g. oil and gas platforms, offshore wind farms), seismic surveys }\end{array}$ \\
and sonar systems, which is widespread in the region. \\
and/or \\
High activity and increasing trend of shipping (commercial and \\
recreational) indicated by the number of tourist vessels and commercial \\
shipping activity (number and intensity of shipping lanes) over widespread \\
areas of the region.
\end{tabular}

High activity of shipping (commercial and recreational) indicated by the number of tourist vessels and commercial shipping activity (number and intensity of shipping lanes) in some sub regions or an increasing trend in some areas.

Low (1) Little offshore construction works using pile driving throughout or moderate activity only in a few places (local or site under the pressure assessment) in the region.

or

Little shipping activity throughout or moderate activity only in a few places in the region (local or site).

570 Confidence assessment criteria: 
and

Information available for that descriptor is easy to interpret in terms of the criteria

and

There is complete agreement amongst experts in the group

Moderate Good quality information is available for some criteria used for the assessment

and/or

There is some information available for all criteria

and/or

Information that is available for that descriptor can be interpreted in terms of the criteria with expert judgement

and

There is majority agreement amongst experts within the group

Low Information is available for few criteria used in the assessment

and/or

There were difficulties with interpretation of available information in terms of the criteria used for the assessment

and/or

The group could not reach a common agreement about the risk score 


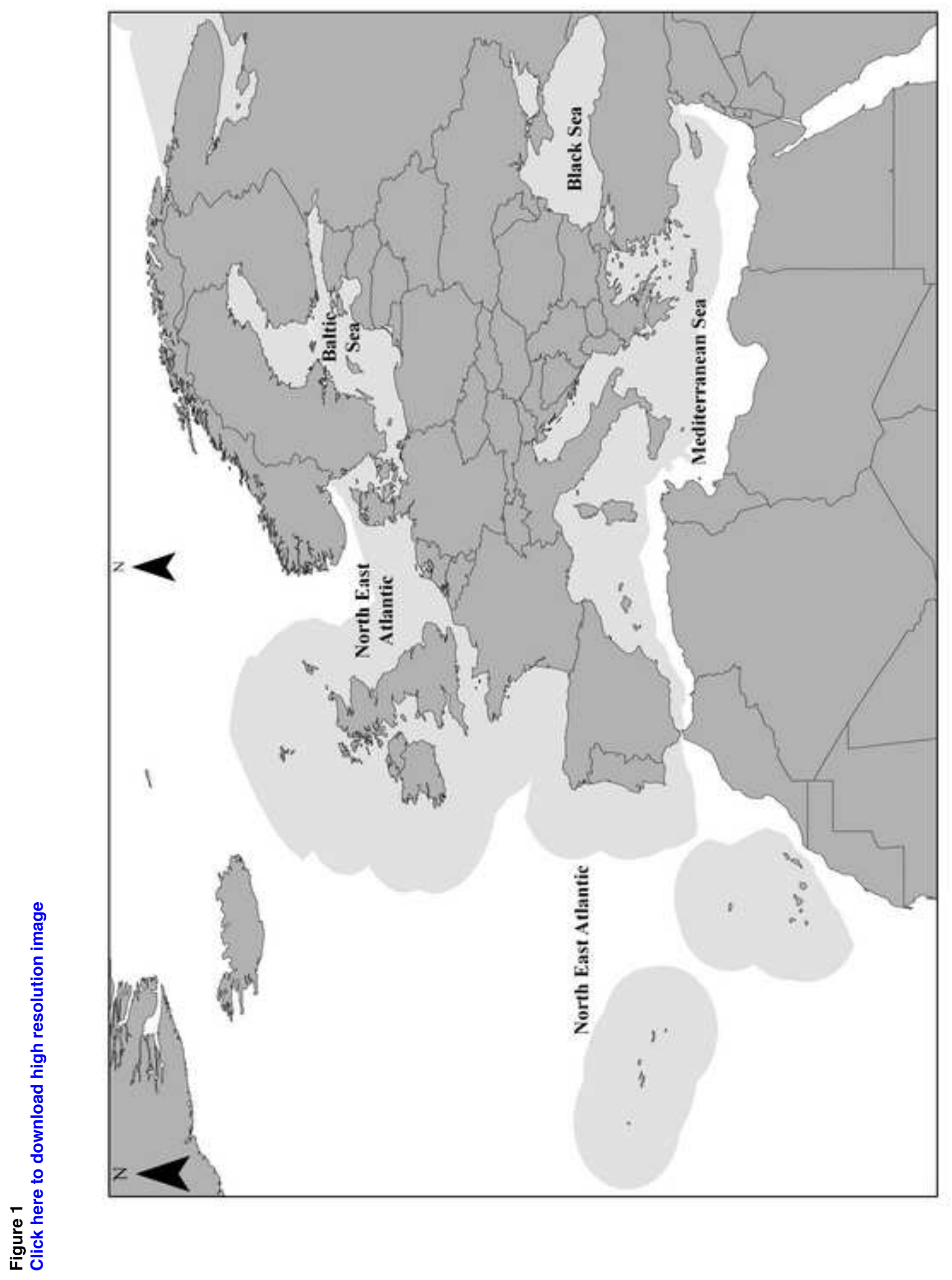

